\title{
MODELING OF BURGER PARAMETERS FOR CMC-GUAR GUM BASED POLYMER NETWORK
}

\author{
G. Bengusu Tezel ${ }^{1}$, Sibel Uzuner ${ }^{2 *}$, Nese Keklikcioglu Cakmak ${ }^{3}$
}

\author{
${ }^{1}$ Department of Chemical Engineering, Faculty of Engineering and Architecture, \\ Abant Izzet Baysal University, Bolu, Turkey \\ ${ }^{2}$ Department of Food Engineering, Faculty of Engineering and Architecture, \\ Abant Izzet Baysal University, Bolu, Turkey \\ ${ }^{3}$ Department of Chemical Engineering, Faculty of Engineering, \\ Cumhuriyet University, Sivas, Turkey
}

Geliş / Received: 24.12.2016; Kabul / Accepted: 30.04.2017; Online bask1 / Published online: 26.04.2017

Tezel, G. B., Uzuner, S., Cakmak, N. K. (2017). Modeling of burger parameters for CMC-guar gum based polymer network. GIDA (2017) 42 (4): 413-421 doi: 10.15237/gida.GD16111

\begin{abstract}
Different gum concentrations of carboxymethyl cellulose (CMC)-guar gum (GG) mixtures (1.5, 2.0, $2.5 \%)$ and their volumetric mixing ratio $(25: 75,50: 50,75: 25)$ were analyzed for Burger model parameters by using response surface design approach based on creep-recovery measurements at $15,25,35^{\circ} \mathrm{C}$. Four component Burger model was used to characterize viscoelasticity of gum mixtures with experimental creep-recovery responses $\left(J_{0}, J_{1}, t_{1}, \eta_{0}, J r_{0}, J r_{1}\right.$ and $\left.t r_{1}\right)$ and it was found to be satisfactory $\left(R^{2}=0.82-0.99\right)$ for the determination of the creep-recovery properties of gum mixtures. The high ratio of GG in concentrated CMC-GG mixture provided an increase in the elasticity in the strong or stiffer structure of gum mixtures at especially low temperatures when it was compared to CMC. However, at high temperature viscous property of the CMC-GG mixture was dominant. It was found that regressed parameters from Burger model were highly dependent to temperature with respect to both volumetric mixing ratio and concentration.
\end{abstract}

Keywords: Burger model, creep-recovery responses, CMC-GG mixture, viscoelasticity, rheology, response surface methodology

\section{CMC-GUAR GAM POLIMER AĞI İÇINN BURGER MODELINE AIIT PARAMETRELERIN MODELLENMESI}

Öz

Karboksimetil selüloz (CMC)-guar gam (GG) karışımlarının sünme-geri dönüş ölçümlerine dayanan Burger model parametreleri farklı gam konsantrasyonları (\%1.5, 2.0, 2.5) ve hacimsel gam karısım oranları $(25: 75,50: 50,75: 25)$, farklı sıcaklıklarda $\left(15,25,35^{\circ} \mathrm{C}\right)$ yanıt yüzey yaklaşımı kullanılarak analiz edilmiştir. Dört bileşenli burger model ve deneysel sünme-geri dönüş özelliklerinden yaralanarak $\left(J_{0}, J_{1}, t_{1}, \eta_{0}, J r_{0}, J r_{1}\right.$ ve $\left.t r_{1}\right)$ gam karışımlarının viskoelastikiyeti karakterize edilmiştir ve gam karışımlarının sünme-geri dönüş özelliklerinin belirlenmesinde bu model $\left(R^{2}=0.82-0.99\right)$ tatmin edici bulunmuştur. Özellikle düşük sıcaklıklarda, yüksek GG içeren konsantre gam karışımları CMC ile karşılaştırıldığı zaman karışımın elastisitesini ve mukavemetini arttırmıştır. Öte yandan, yüksek sıcaklıkta karışımın viskoz özelliği baskındır. Burger model regresyon parametrelerinin hacimsel CMC-GG karışım oranı ve konsantrasyonuna kiyasla daha çok sıcaklığa bağlı olduğu bulunmuştur.

Anahtar kelimeler: Burger modeli, sünme-geri dönüş yanıtları, CMC-GG karışım, viskoelastikiyet, reoloji, yanıt yüzey yöntemi

\footnotetext{
* Yazışmalardan sorumlu yazar / Corresponding author;

๑) suzuner81@yahoo.com, (c) (+90) 374254 1000/4875, 且 (+90) 3742534558
} 


\section{INTRODUCTION}

Gums are the main ingredients in foods as a thickening and gelling agents to control viscosity (1). The use of two or more gums in a mixture is a common practice in the food industry due to synergistic interaction between or among themselves (1). Guar gum (GG) is used as an economical thickening and stabilizing agents in the food industry and is often combined with xanthan gum (XG), locust bean gum (LBG), or carboxymethyl cellulose (CMC) to increase synergistic changes in viscosity or gelling behaviour of complex food stucture (2).

When gums- either individually or in mixturewere used viscosity of that particular food need to be controlled as the rheological characterization of a mixed gums is important for product quality and shelf life. Due to viscoelastic nature of gums, elastic and viscous properties of gum solutions can be measured using small amplitude oscillatory shear (SAOS) and creep recovery tests as SAOS test gives the knowledge of dynamic properties such as elastic modulus $\left(G^{\prime}\right)$ and loss modulus $\left(G^{\prime \prime}\right)$ in the linear viscoelastic region range (3). Creep-recovery tests are the most commonly used methods to define viscoelastic properties of materials (3). Creep and recovery are coupled test that creep test is obtained by applying a constant shear stress to the material, and deformation (strain) is recorded over the creep time. In the recovery part, shear stress is removed and again deformation is recorded over recovery time. The deformation supplies the alteration in molecular structure of material during this test. Burger model which is combined with Maxwell (4) and Kelvin-Voigt Model (5) connected in series determines the stress relaxation characteristics of viscoelastic samples from the resulting creep and recovery rheological measurement. This model is a mechanistic approach of viscoelasticity to simulate the linear relaxation of real viscoelastic materials at the small material strains. Each regressed coefficients $\left(J_{0}, J_{1}, t_{1}, \eta_{o}, J r_{0}, J r_{1}\right.$ and $\left.t r_{1}\right)$ of Burger model signify to distinct viscoelastic characterization of mixed gums.

However, there is a limited number of studies on Burger model application into complex food or non-food systems. For example, Chompoorat et al. (6) analyzed diacetyl tartaric acid ester of monoglycerides (DATEM), ascorbic acid (AA), urea, and dithiothreitol (DTT) on viscoelastic properties of gluten using Burgers model. It was found that Burger model coefficients served as a tool to explain changing viscoelastic nature of gluten mixtures. On the other hand, Dogan et al. (7) used Burger model to find optimum gum mixtures which provides the highest resistance to deformation on pudding samples. Another study of Dogan et al. (8) is also related to the Burger model simulation on viscoelastic properties of ice cream samples as a function of different xanthan gum concentrations. Common side of these studies is the applicability of Burger model into complex food structured system using mechanical approach. From regressed Burger coefficients, it is possible to control physical characteristics related to the improvement of product design and quality. But, to our best knowledge there is no prior study on CMC-GG mixed gums based on creep-recovery parameters of the gum combination using Burger model.

Prediction of deformation knowledge of mixed gums with respect to different working conditions helps us to design and develop of new food materials for food industry. The aim of this study is to investigate effects of concentration of CMCGG solutions, temperature and volumetric mixing ratio (CMC/GG) and their interaction terms on the creep-recovery parameters of CMCGG mixture samples by modeling their viscoelastic behavior using Burger Model and to determine the relation between the regressed coefficients at the different design levels.

\section{MATERIALS AND METHODS}

\section{Materials}

Polymer powders of guar gum (GG) and sodium carboxylmethyl cellulose (CMC) (Sigma-Aldrich Corp, St Louis, MO), with nominal molecular weight of $700,000 \mathrm{~g} / \mathrm{mol}$ were kindly provided by Dr. Kerim YAPICI, Department of Nanotechnology Engineering, Cumhuriyet University, Sivas, Turkey.

\section{Preparation of gum solutions}

The CMC and GG powders were dissolved in distilled water separately at $25^{\circ} \mathrm{C}$ for $6 \mathrm{~h}$ using a magnetic stirrer with gentle shaking in order to prepare $1.5,2$ and $2.5 \%(\mathrm{w} / \mathrm{v})$ stock solutions of $\mathrm{CMC}$ and GG. The CMC stock solution was 
thoroughly mixed operated at $150 \mathrm{rpm}$ with GG solution at different volumetric mixing ratios of CMC:GG, such as 75:25; 50:50 and 25:75, respectively.

\section{Measurements of rheological properties}

Creep and recovery tests of the samples measurements were performed by using a stress controlled rheometer (Malvern Kinexus Pro, UK) fitted by a cone-and-plate system $(50 \mathrm{~mm}$ diameter, $1^{\circ}$ cone angle). A peltier plate assembly was used for temperature controlling purpose during the measurements with $\pm 0.1{ }^{\circ} \mathrm{C}$ precision. Strain amplitude sweep over a stress was carried out under constant frequency to determine linear viscoelastic region storage. Elastic modulus $\left(G^{\prime}\right)$ and loss modulus $\left(G^{\prime \prime}\right)$ of each sample changing with respect to oscillatory stress at a constant frequency of $1 \mathrm{~Hz}$ are given in Figure 1.

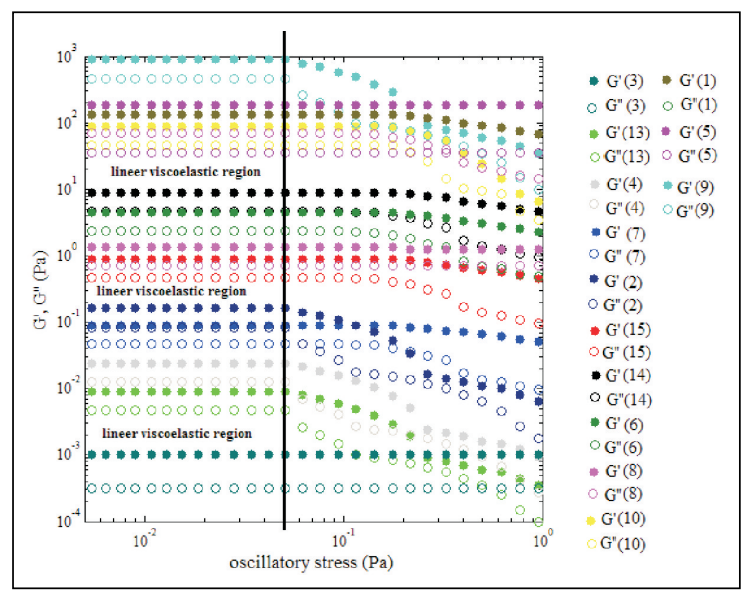

Figure 1. Variation of the loss $\left(G^{\prime}\right)$ and storage $\left(G^{\prime}\right)$ modulus with oscillatory stress at $1 \mathrm{~Hz}$ for all design samples

In the figure all curves show common viscoelastic region up to $0.05 \mathrm{~Pa}$ characterized by a constant modulus with respect to stress. So, creep- recovery tests were carried out under the constant shear stress of $0.05 \mathrm{~Pa}$ (in linear viscoelastic region) at three different temperatures $\left(15,25\right.$, and $\left.35^{\circ} \mathrm{C}\right)$ to measure the deformation of mixtures. All experiments were conducted in duplicate.

Creep-recovery tests include two parts, one of which is creep phase in which $0.05 \mathrm{~Pa}$ constant stress was applied for $120 \mathrm{~s}$ and the compliance values were recorded as a function of time. In the second part, which is recovery part, the applied stress was removed and then compliance values were also obtained as a func-tion of time for 120 s. In creep-recovery test, the stress response of samples under constant stress in a total time of $240 \mathrm{~s}$ was measured. Compliance value $\left(J c(t), \mathrm{Pa}^{-1}\right)$ shows deformation of mixed gums per unit stress as function of time (9) (data not shown).

\section{Burger model}

The effect of concentration of CMC-GG solutions, temperature and volumetric mixing ratio (CMC/GG) on the creep-recovery characteristics data of CMC-GG mixed gel were fitted into Burger model (10). Burger model has been commonly applied to study viscoelastic behavior of soft matter (11). Deformation behavior of material also was described by using Burger model coefficients. These regressed parameters from the model are given with the near corresponding compliance values depicted in Figure 2.

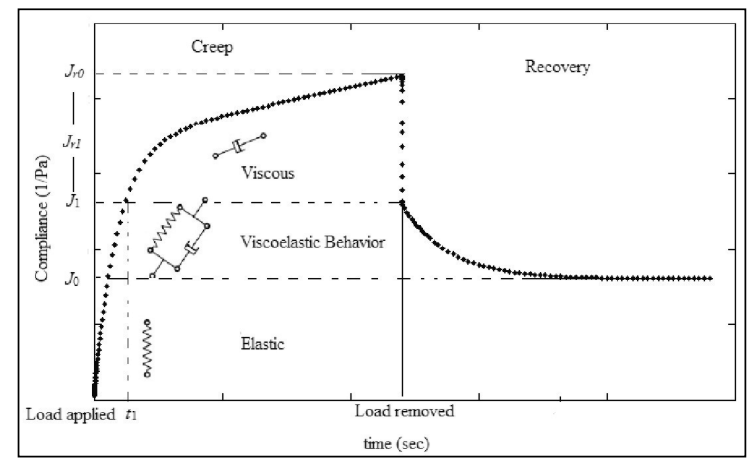

Figure 2. General representation of Burger creep and recovery model

Burger model, a combination of Maxwell and Kelvin-Voigt model, is represented by a spring and a dashpot; while, a parallel arrangement between spring and dashpot is used in KelvinVoigt model. It has two constitutive equations for creep and recovery parts. Equation (1) shows the model during creep:

$J c(t)=J_{0}+J_{1}\left(1-\exp \left(\frac{-t}{t_{1}}\right)\right)+\frac{t}{\eta_{0}} \quad$ Equation (1)

where, $J c(t)$ is creep compliance as function of time $(t)$. The first element of Burger model is instantaneous shear compliance $\left(J_{0}\right)$ corresponding to a spring or elastic modulus. The second element is delayed or retarded viscoelasticity $\left(J_{1}\right)$. Retardation time $\left(t_{1}\right)$ is a time of delayed elastic deformation. The last element is related to the 
zero shear rate viscosity of gum mixture $\left(\eta_{0}\right)$. This element corresponds to an increase in deformation of dashpot. Burger model also yields recovery characteristics of gum mixtures. Equation (2) shows the Burger model during recovery:

$J r(t)=J_{r 0}+J_{r 1}\left(1-\exp \left(\frac{t}{t_{r 1}}\right)\right)$

Equation (2)

Equation (2) contained only 3 elements because there is no dashpot (pure viscous) during recovery phase. $J_{r 0}$ is the first part of recovery, corresponds to the spring of the Maxwell element. $J_{r 1}$ is the second recovery due to the Kelvin-Voigt element. $t_{r 1}$ represents the time that takes the gum mixture recovery step required for the elastic recovery of gum mixture.

\section{Experimental design and statistical analysis}

Response surface design was used to observe the effect of GG and CMC mixed gum on the parameters of the sample obtained from creep and recovery measurements. The relationship between the responses of $\mathrm{J} 0, \mathrm{~J} 1, \mathrm{t} 1, \ldots 0, \mathrm{Jr} 0, \mathrm{Jr} 1$ and tr1 values and independent variables of temperature, concentration of CMC-GG solutions and volumetric mixing ratio (CMC/GG) were examined by using the Box-Behnken Design (BBD) with a quadratic model. A second order polynomial model was fitted to represent linear, interaction and quadratic effects of variables on Burger pa- rameters. The experimental design of Box-Behnken model is represented in Table 1. A, B and C are values of temperature, concentration of CMCGG solutions and volumetric mixing ratio (CMC/GG), respectively. The analysis was also performed in duplicates. The analysis of variance (ANOVA) and regression analysis were performed to define the coefficients of the predictive model and significant terms using MINITAB 16.0 (Minitab Inc. State College, PA, USA). The coefficient of determination (R2) was determined to check for the linearity between the predicted vs. experimental Burger parameters. Statistical analyses were accomplished using MINITAB 16.0 to test the significance of different rheological properties of mixed gums. The pairwise comparisons were made by Tukey's test with a significance level of 0.05 . Pareto charts were plotted to represent the standardized effects of concentration of CMC-GG solutions, temperature and volumetric mixing ratio (CMC/GG) (via $\mathrm{T}$ values) on Burger model parameters such as J0, J1, t1, _0, $\mathrm{Jr} 0, \mathrm{Jr} 1$ and tr1 values.

\section{RESULTS AND DISCUSSION}

By calculating creep and recovery parameters of Burger model, the information of internal structure of gum mixtures at a given volumetric mixing ratio and temperature levels was obtained. All related model parameters were illustrated in Table 2 and Table 3.

Table 1. Experimental design for Burger model parameters using Box-Behnken response surface method (RSM)

\begin{tabular}{cccc}
\hline Sample No. & $\begin{array}{c}\text { Temperature }\left({ }^{\circ} \mathrm{C}\right) \\
(\mathrm{A})\end{array}$ & $\begin{array}{c}\text { Concentration of CMC-GG } \\
\text { solutions }(\%)(\mathrm{B})\end{array}$ & $\begin{array}{c}\text { Volumetric mixing ratio } \\
(\mathrm{CMC} / \mathrm{GG})(\mathrm{C})\end{array}$ \\
\hline 1 & 35 & 1.5 & $50: 50$ \\
2 & 25 & 2.0 & $50: 50$ \\
3 & 15 & 1.5 & $50: 50$ \\
4 & 15 & 2.0 & $25: 75$ \\
5 & 35 & 2.0 & $25: 75$ \\
6 & 25 & 2.5 & $75: 25$ \\
7 & 15 & 2.5 & $50: 50$ \\
8 & 25 & 1.5 & $25: 75$ \\
9 & 35 & 2.5 & $50: 50$ \\
10 & 35 & 2.0 & $75: 25$ \\
11 & 25 & 2.0 & $50: 50$ \\
12 & 25 & 2.0 & $50: 50$ \\
13 & 15 & 2.0 & $75: 25$ \\
15 & 25 & 2.5 & $25: 75$ \\
\hline
\end{tabular}


Modeling of Burger Parameters for CMC-GAR Gub Based...

Table 2. Creep model parameters of the mixed gum obtained from fitting of Eq.2*

\begin{tabular}{|c|c|c|c|c|c|}
\hline Sample No. & $J_{0}\left(\mathrm{~Pa}^{-1}\right)$ & $J_{1}\left(\mathrm{~Pa}^{-1}\right)$ & $t_{1}(\mathrm{~s})$ & $\eta_{0}$ (Pa.s) & $R^{2}$ \\
\hline 1 & $0.020 \pm 0.002^{e}$ & $2.899 \pm 0.011^{\mathrm{cd}}$ & $8.253 \pm 0.141^{\text {bcde }}$ & $83.230 \pm 4.240^{\dagger}$ & $0.988 \pm 0.001$ \\
\hline 2 & $0.044 \pm 0.003^{\mathrm{ab}}$ & $1.605 \pm 0.010^{\text {efg }}$ & $7.605 \pm 0.735^{\mathrm{de}}$ & $192.690 \pm 10.670^{\circ}$ & $0.993 \pm 0.001$ \\
\hline 3 & $0.020 \pm 0.001^{\mathrm{e}}$ & $0.909 \pm 0.025^{9}$ & $5.085 \pm 0.001^{\dagger}$ & $249.550 \pm 0.960^{b}$ & $0.993 \pm 0.002$ \\
\hline 4 & $0.030 \pm 0.002^{d}$ & $1.916 \pm 0.014^{\mathrm{ef}}$ & $8.106 \pm 0.030^{\text {bcde }}$ & $258.450 \pm 2.360^{\mathrm{ab}}$ & $0.988 \pm 0.004$ \\
\hline 5 & $0.035 \pm 0.001^{c d}$ & $3.143 \pm 0.222^{\mathrm{bcd}}$ & $10.951 \pm 0.233^{a}$ & $63.180 \pm 5.580^{9}$ & $0.982 \pm 0.006$ \\
\hline 6 & $0.047 \pm 0.001^{\mathrm{a}}$ & $3.879 \pm 0.397^{\mathrm{ab}}$ & $9.560 \pm 0.671^{\mathrm{abc}}$ & $211.340 \pm 2.980^{\text {cd }}$ & $0.994 \pm 0.000$ \\
\hline 7 & $0.029 \pm 0.000^{d}$ & $2.518 \pm 0.211^{\mathrm{de}}$ & $8.205 \pm 0.113^{\text {bcde }}$ & $271.750 \pm 1.980^{\mathrm{a}}$ & $0.996 \pm 0.001$ \\
\hline 8 & $0.043 \pm 0.005^{\mathrm{ab}}$ & $3.705 \pm 0.120^{\mathrm{abc}}$ & $9.105 \pm 0.028^{\mathrm{abcd}}$ & $214.330 \pm 2.970^{c d}$ & $0.995 \pm 0.001$ \\
\hline 9 & $0.032 \pm 0.000^{\mathrm{cd}}$ & $4.324 \pm 0.490^{\mathrm{a}}$ & $10.195 \pm 0.098^{\mathrm{a}}$ & $62.190 \pm 2.730^{\circ}$ & $0.994 \pm 0.003$ \\
\hline 10 & $0.028 \pm 0.000^{d}$ & $3.069 \pm 0.080^{\mathrm{bcd}}$ & $9.492 \pm 0.212^{\mathrm{abcd}}$ & $73.070 \pm 3.540^{\text {tg }}$ & $0.991 \pm 0.005$ \\
\hline 11 & $0.038 \pm 0.002^{\mathrm{bc}}$ & $1.455 \pm 0.067^{\mathrm{tg}}$ & $7.700 \pm 0.071^{\text {de }}$ & $200.650 \pm 0.760^{d e}$ & $0.989 \pm 0.005$ \\
\hline 12 & $0.046 \pm 0.000^{\mathrm{a}}$ & $1.613 \pm 0.021^{e^{f g}}$ & $7.105 \pm 0.028^{e}$ & $203.730 \pm 4.950^{\text {cde }}$ & $0.987 \pm 0.008$ \\
\hline 13 & $0.029 \pm 0.000^{d}$ & $1.618 \pm 0.071^{e f g}$ & $9.099 \pm 0.040^{\mathrm{abcd}}$ & $266.730 \pm 2.120^{\mathrm{a}}$ & $0.984 \pm 0.018$ \\
\hline 14 & $0.045 \pm 0.001^{\mathrm{a}}$ & $4.196 \pm 0.006^{a}$ & $9.936 \pm 1.203^{\mathrm{ab}}$ & $218.790 \pm 2.040^{\circ}$ & $0.992 \pm 0.001$ \\
\hline 15 & $0.048 \pm 0.000^{\mathrm{a}}$ & $3.637 \pm 0.534^{\mathrm{abc}}$ & $9.713 \pm 0.888^{\mathrm{ab}}$ & $202.890 \pm 0.930^{\text {cde }}$ & $0.993 \pm 0.002$ \\
\hline
\end{tabular}

* Values followed by the same letter in a column are statistically different $(p<0.05)$

Table 3. Recovery model parameters of the mixed gum obtained from fitting of Eq.3*

\begin{tabular}{ccccc}
\hline Sample No. & $J r_{0}\left(\mathrm{~Pa}^{-1}\right)$ & $J r_{1}(\mathrm{~Pa}-1)$ & $\operatorname{tr}_{1}(\mathrm{~s})$ & $R^{2}$ \\
\hline 1 & $56.790 \pm 0.620^{\mathrm{c}}$ & $55.790 \pm 0.630^{\mathrm{c}}$ & $39.030 \pm 0.550^{\mathrm{a}}$ & $0.989 \pm 0.003$ \\
2 & $248.890 \pm 0.250^{\mathrm{b}}$ & $248.070 \pm 0.080^{\mathrm{b}}$ & $21.602 \pm 0.790^{\mathrm{b}}$ & $0.993 \pm 0.002$ \\
3 & $357.060 \pm 0.100^{\mathrm{a}}$ & $356.680 \pm 0.420^{\mathrm{a}}$ & $18.080 \pm 0.000^{\mathrm{b}}$ & $0.993 \pm 0.002$ \\
4 & $357.400 \pm 0.580^{\mathrm{a}}$ & $356.200 \pm 0.030^{\mathrm{a}}$ & $19.090 \pm 0.020^{\mathrm{b}}$ & $0.988 \pm 0.004$ \\
5 & $56.890 \pm 1.170^{\mathrm{c}}$ & $55.740 \pm 0.860^{\mathrm{c}}$ & $39.900 \pm 1.320^{\mathrm{a}}$ & $0.991 \pm 0.007$ \\
6 & $249.610 \pm 0.680^{\mathrm{b}}$ & $249.030 \pm 0.020^{\mathrm{b}}$ & $20.280 \pm 0.000^{\mathrm{b}}$ & $0.994 \pm 0.000$ \\
7 & $356.860 \pm 0.070^{\mathrm{a}}$ & $356.300 \pm 0.060^{\mathrm{a}}$ & $21.090 \pm 0.390^{\mathrm{b}}$ & $0.996 \pm 0.001$ \\
8 & $249.140 \pm 0.070^{\mathrm{b}}$ & $248.050 \pm 0.040^{\mathrm{b}}$ & $19.610 \pm 0.330^{\mathrm{b}}$ & $0.995 \pm 0.001$ \\
9 & $58.180 \pm 0.070^{\mathrm{b}}$ & $55.180 \pm 0.080^{\mathrm{b}}$ & $40.230 \pm 0.803^{\mathrm{a}}$ & $0.994 \pm 0.003$ \\
10 & $56.440 \pm 0.070^{\mathrm{c}}$ & $55.570 \pm 0.350^{\mathrm{c}}$ & $37.180 \pm 2.820^{\mathrm{a}}$ & $0.996 \pm 0.002$ \\
11 & $249.604 \pm 0.020^{\mathrm{b}}$ & $248.570 \pm 0.780^{\mathrm{b}}$ & $21.090 \pm 0.050^{\mathrm{b}}$ & $0.989 \pm 0.005$ \\
12 & $249.002 \pm 0.060^{\mathrm{b}}$ & $248.040 \pm 0.000^{\mathrm{b}}$ & $21.470 \pm 0.540^{\mathrm{b}}$ & $0.992 \pm 0.001$ \\
13 & $357.205 \pm 0.180^{\mathrm{b}}$ & $356.530 \pm 0.480^{\mathrm{a}}$ & $18.480 \pm 0.340^{\mathrm{b}}$ & $0.992 \pm 0.006$ \\
14 & $253.420 \pm 6.120^{\mathrm{b}}$ & $252.190 \pm 5.880^{\mathrm{b}}$ & $19.080 \pm 0.140^{\mathrm{b}}$ & $0.992 \pm 0.001$ \\
15 & $249.510 \pm 0.450^{\mathrm{b}}$ & $248.530 \pm 0.750^{\mathrm{b}}$ & $21.050 \pm 0.330^{\mathrm{b}}$ & $0.993 \pm 0.002$ \\
\hline
\end{tabular}

** Values followed by the same letter in a column are statistically different $(p<0.05)$

It was found that $J_{0}$ values were smaller than $J_{1}$ leading to higher viscoelastic behavior than elastic nature of gum mixtures. At the maximum concentration of CMC and GG solutions level $(2.5 \%), J_{1}$ values were higher due to intermolecular interaction between GG-CMC mixture depended strongly on the concentration of CMC and GG solutions. The interactive effects of significant variables were represented in contour plots as shown in Figure 3.

The maximum response is referred to a surface confined in the smallest ellipse in a contour plot. The perfect interaction between the independent variables can be shown when elliptical contours are obtained (11). Figure 3 a shows that the effect of concentration of CMC and GG solutions and temperature on $J_{1}$ with the interactive effect of concentration of CMC and GG solutions and positive significant effect of temperature (Figure 3a). As shown in Figure 3a, the viscoelastic response, $J_{1}$, for high volumetric mixing ratio of GG was significantly increased as the temperature increased. Especially, $J_{1}$ reached maximum value of $4.19 \mathrm{~Pa}^{-1}\left(25^{\circ} \mathrm{C}\right)$ at high concentration of CMC and GG solutions (2.5\%) and GG ratio (25:75) in the mixture (Table 2). Higher content of GG caused an increase in the viscoelasticity by $7.55 \%$ when compared to CMC (Table 2 , Samples 6 and 14). Moreover, increased temperature also provided an increasing effect on the viscoelasticity (Table 2, Samples 4 and 5). For creep phase parameter of $J_{1}$, the increase in the ratio of GG reinforced the viscoelastic structure of mixed gum by decreasing the viscosity especially at high concentration of $2.5(\%)$ at $35^{\circ} \mathrm{C}$ 
as in Figure $3 \mathrm{a}$. At $35^{\circ} \mathrm{C}$, maximum viscoelasticity was also observed with high mixing concentration ratio of 50:50 (Table 2, Sample 9). Hence, higher permanent deformation of mixed gum was obtained at high values of $J_{1}$.

When highly extend of GG in mixture, the viscoelasticity of gum mixture can be attributed
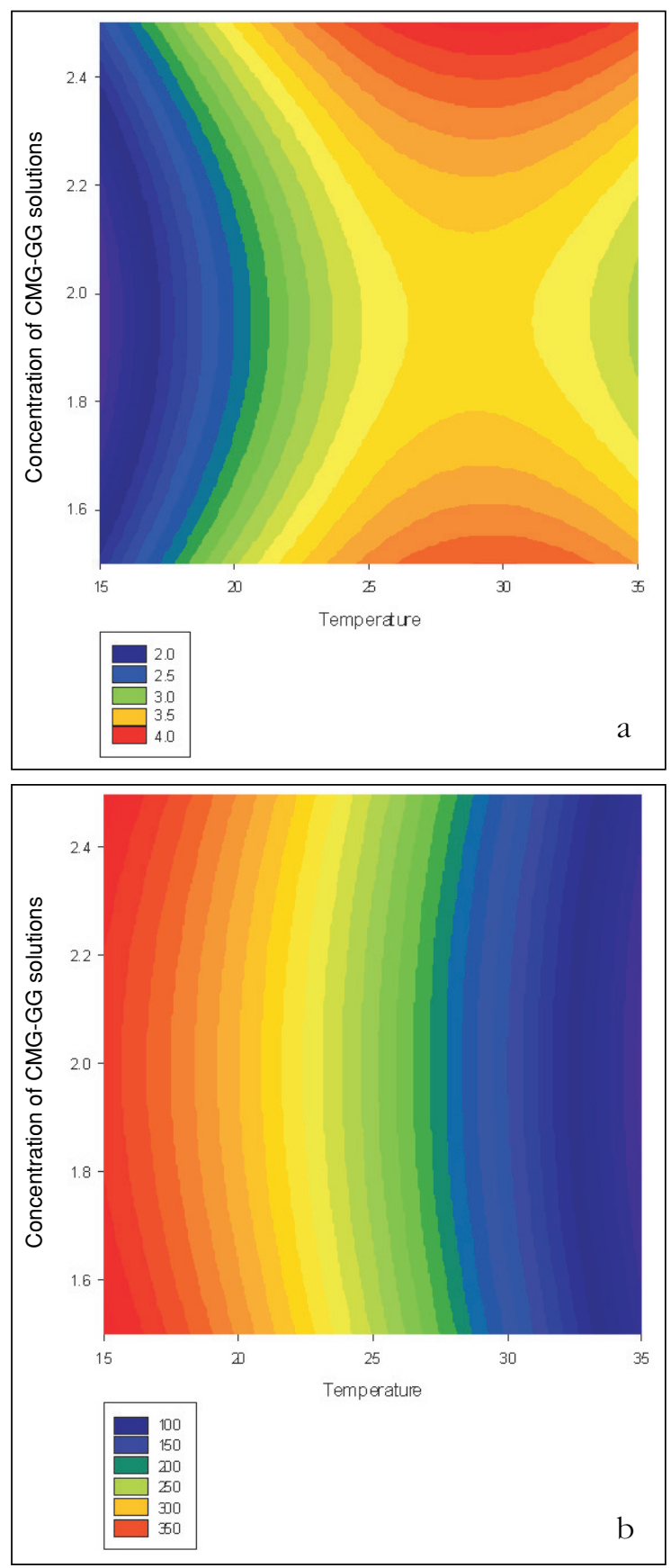

Figure 3. Contour plots showing interactive effect of concentration of CMC-GG solutions and temperature for a) $J_{1}$, b) $J r_{1}$ at constant volumetric mixing ratio gum ratio (25:75). to entanglement network structure due to more elastic nature of GG than that of CMC. On the other hand, retardation time, $t_{1}$ was directly related to viscoelastic properties which was similar to $J_{1}$. So, it has showed similar trends as in $J_{1}$. Increasing concentration of CMC and GG solution did not significantly change $t_{1}(P>0.05)$, but it was highly dependent on the mixed gum ratio. $\eta_{0}$ gives the degree of zero shear rate viscosity of gum mixtures and was significantly changed with temperature. $\eta_{0}$ values ranged at 62.19-266.73 (Pa.s) (Table 2). It was noted that $\eta_{0}$ values decreased with increasing temperature (Sample 5 and 9, Table 2). A significant synergetic effect of CMC-GG mixture was also observed even at low concentration (1.5\%) and the ratio of 50:50 mixture. Thus, the viscous behavior of CMC-GG solutions also increased up to 83 Pa.s at $35{ }^{\circ} \mathrm{C}$ (Table 2). However, it was found that gum mixtures showed higher $\eta_{0}$ values which were expressed more stiff structure of gum mixture at $15^{\circ} \mathrm{C}$.

In recovery phase, $J r_{O}$ is related to the elastic nature of gum mixture, whereas $J r_{1}$ is related to the viscoelastic behavior of concentration of CMC and GG solutions (Table 3). These parameters showed the same trend in which their values considerably changed with temperature. Effect of CMC and GG solutions's concentration and temperature on $J r_{1}$ represented in Figure 3 . Increasing temperature, recovery coefficients remarkably decreased due to viscous deformation of gum mixtures and irreversibly deformation of elastic chains between CMC-GG molecules. Also, $t r_{1}$ values reached to higher values at $35^{\circ} \mathrm{C}$ (Table 3). On the other hand, at low temperature, recovery was obtained at a shorter time after the applied deformation, and gum mixtures became more stiff structure. For example, at $15^{\circ} \mathrm{C}$, viscoelastic recovery coefficients amplified to the order of $350 \mathrm{~Pa}^{-1}$ due to giving quick response of gum chains compared to $35^{\circ} \mathrm{C}$ when the applied force removed at high volumetric mixing (CMC/GG) ratio in the mixture.

After the determination of the Burger model parameters of the CMC-GG mixed gum, BoxBenhken design was applied to model as a function of temperature, concentration of CMC and $\mathrm{GG}$ solutions, and volumetric mixing ratio (CMC/GG). Table 4 represents the established 
predicted models, constants, coefficient of determination values $\left(R^{2}\right)$ and lack of fit values. $R^{2}$ values of the creep model parameters for $J_{0}, J_{1}$, $t_{1}$ and $\eta_{0}$ values were in the range of $0.82-0.99$, whereas $R^{2}$ values of the recovered model parameters for $J r_{0}, J r_{1}$ and $t r_{1}$ values were in the range of 0.98-0.99. There was also insignificant lack of fit for all models. The degree of efficacy of varying process conditions on the burger parameters can be deduced by comparing the magnitude of the coefficients of the second order model (Table 4). Temperature is the most important factor with the highest coefficient 0.016, 0.0809, 1.049, 95.59, 150.01, 150.43 and 9.95 for $J_{o}, J_{1}, t_{1}$, $\eta_{0}, J r_{0}, J r_{1}$ and $t r_{1}$ values, respectively (Table 4).

The standardized effect of the independent variables (concentration of CMC and GG solutions, temperature and volumetric mixing ratio (CMC/GG), quadratic effects and their interactions on Burger model parameters such as $J_{0}, J_{1}, t_{1}, \eta_{o}$, $J r_{0}, J r_{1}$ and $t r_{1}$ values was also visualized by Pareto chart (Figures 4a-g), in which the process variables below the vertical line are considered insignificant and those above the line with a negative sign also implied significant effect but in opposite mode. Thus, only temperature and gum concentration positively affected $J_{1}, t_{1}$ and $t r_{1}$, whereas only gum concentration had a positive effect on $J_{o}$ (Figures 4a-g).

\section{CONCLUSIONS}

Creep and recovery Burger model parameters of CMC-GG gum mixtures were analyzed with respect to temperature, concentration of CMC and $\mathrm{GG}$ solutions, and volumetric mixing ratio (CMC/GG). CMC-GG mixtures were also modeled in order to characterize distinct elastic, viscoelastic and viscous behavior of gum mixture using response surface design method in terms of Burger model parameters. The model was confirmed that parameters from Burgers model could assist in explaining changes in rheological structures. All elastic coefficients were found smaller order than viscoelastic coefficients. Viscoelastic characteristics of gum mixture were more pronounced at higher ratio of GG indicating a higher regressed viscoelastic coefficients of $G G$ than CMC especially in concentrated gum mixture. On the other hand, recovery coefficients were found highly temperature dependent due to higher contribution of viscous deformation of gum mixtures and irreversibly deformed elastic chains between GG-CMC molecules at high temperature.

\section{ACKNOWLEDGEMENTS}

The authors would like to thank Dr. Kerim Yapicı at the Cumhuriyet University Nanotechnology Engineering Laboratory, Sivas, Turkey, for providing with stress controlled rheometer and all materials used in the experiments.

\section{REFERENCES}

1. Tziboula A, Horne DS. 2000. Gums and Stabilisers for the Food Industry, 2nd ed., RSC: Cambridge.

2. Mohsenin NN, Mittal JP. 1977. Use of rheological terms and correlation of compatible measurements in food texture research. J Texture Stud, 8: 395-408.

3. Barnes HA, Hutton JF, Walters K. 1989. An Introduction to Rheology. J Non-Newton Fluid Mech, 32: 331-333.

4. Ferry JD. 1980. Viscoelastic properties of polymers, 3rd ed., John Wiley: New York.

Table 4. Predicted models, $R^{2}$ values and lack of fit values for the parameters of CMC-GG mixed gums

\begin{tabular}{llcccc}
\hline Parameter & Predicted models & $R^{2}$ & $R_{\text {adj }}^{2}$ & $R_{\text {pred }}^{2}$ & Lack of fit \\
\hline$J_{0}$ & $\mathrm{~J}_{0}=0.043-0.016 \mathrm{~A}^{2}+0.004 \mathrm{C}^{2}+0.003 \mathrm{~B}$ & 0.89 & 0.85 & 0.76 & $0.89^{\text {ns }}$ \\
$J_{1}$ & $\mathrm{~J}_{1}=1.558+1.260 \mathrm{~B}^{2}+1.035 \mathrm{C}^{2}+0.809 \mathrm{~A}+0.471 \mathrm{~B}$ & 0.93 & 0.89 & 0.79 & $0.27^{\text {ns }}$ \\
$t_{1}$ & $\mathrm{t}_{1}=7.469+1.793 \mathrm{C}^{2}+1.049 \mathrm{~A}+0.717 \mathrm{~B}$ & 0.82 & 0.77 & 0.70 & $0.16^{\text {ns }}$ \\
$\eta_{0}$ & $\eta_{0}=199.02-39.390 \mathrm{~A}^{2}+7.060 \mathrm{~B}^{2}+5.760 \mathrm{C}^{2}-95.590 \mathrm{~A}-10.810 \mathrm{AB}$ & 0.99 & 0.99 & 0.99 & $0.34^{\text {ns }}$ \\
$\mathrm{Jr}_{0}$ & $\mathrm{Jr}_{0}=249.180-42.720 \mathrm{~A}^{2}-150.010 \mathrm{~A}$ & 0.99 & 0.99 & 0.99 & $0.09^{\text {ns }}$ \\
$\mathrm{Jr}_{1}$ & $\mathrm{Jr}_{1}=248.220-42.840 \mathrm{~A}^{2}-150.430 \mathrm{~A}$ & 0.99 & 0.99 & 0.99 & $0.11^{\text {ns }}$ \\
tr $_{1}$ & $\mathrm{tr}_{1}=21.390+8.440 \mathrm{~A}^{2}-1.170 \mathrm{C}^{2}+9.950 \mathrm{~A}$ & 0.98 & 0.98 & 0.97 & $0.10^{\text {ns }}$ \\
\hline
\end{tabular}

ns: Not significant, A: Temperature, B: Concentration of CMC-GG solutions, C: Volumetric gum ratio 

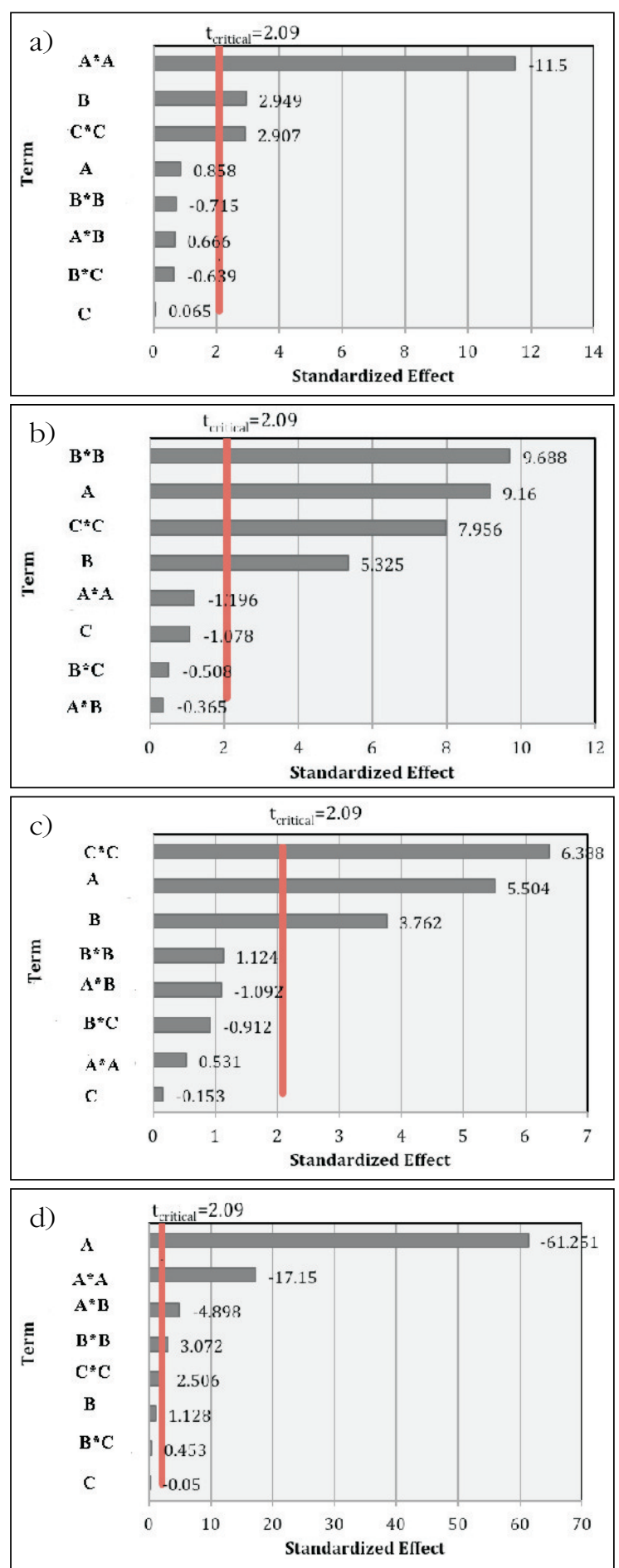

Figure 4. Pareto charts showing the standardized effects of temperature $(A)$, concentration of CMC-GG solutions (B), and volumetric mixing ratio (C) (via $T$ values) on Burger model parameters such as $J_{0}, J_{1}, t_{1}, \eta_{0}, J r_{0}, J r_{1}$ and $t r_{1}$ values.
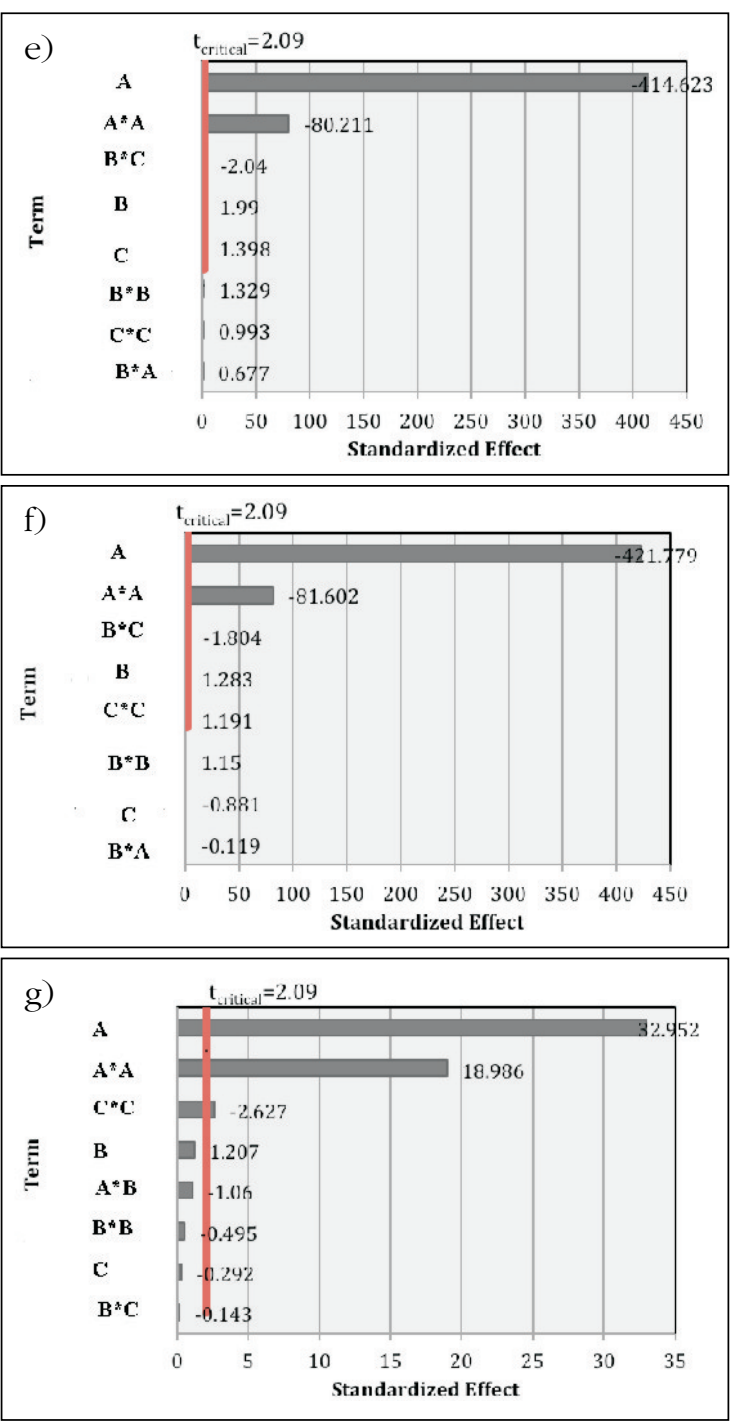

5. Larsen DS, Tang J, Ferguson L, Morgenstern MP, James B. 2015. Textural Complexity is a Food Property - Shown Using Model Foods. Int J Food Prop, 19: 1544-1555.

6. Chompoorat P, Ambardekar A, Mulvaney S, Rayas-Duarte P. 2013. Rheological Characteristics of Gluten after Modified by DATEM, Ascorbic Acid, Urea and DTT Using Creep-Recovery Test. J Mod Phys, 4: 1-8.

7. Dogan M, Ersoz NB, Toker OS, Kaya Y, Caniyllmaz E. 2014. Optimization of gum combination for instant pudding based on creep and recovery parameters by mixture design approach. Eur Food Res Technol, 238: 47-58. 
8. Dogan M, Kayacier A, Toker ÖS, Yilmaz MT, Karaman S. 2013. Steady, dynamic, creep, and recovery analysis of ice cream mixes added with different concentrations of xanthan gum. Food Bioprocess Tech, 6: 1420-1433.

9. Uzuner S, Tezel GB, Cakmak KN. 2016. Effect of temperature, gum concentration and gum ratio on creep-recovery behaviour of carboxymethyl cellulose-guar gum mixtures: modeling with RSM and ANN. Ital J Food Sci, 28: 273- 288.

10. Burgers J. 1939. Mechanical considerations-model systems phenomenological theories of relaxation and of viscosity. First report on viscosity and plasticity, New York, Nordemann.
11. Das S, Ghosh A. 2006. Study of creep, stress relaxation, and inverse relaxation in mulberry (Bombyx mori) and tasar (Antheraea mylitta) silk. J Appl Polym Sci, 99: 3077-3084.

12. Zahangir AM, Suleyman AM, Rosmaziah W.2008. Statistical optimization of process conditions for cellulase production by liquid state bioconversion of domestic wastewater sludge. Bioresour Technol, 99: 4709-4716. 